\title{
Derechos humanos y fenómeno migratorio: entre el abismo del discurso y los hechos
}

\author{
Joaquín A. Mejía R. ${ }^{1}$ y Yolanda González C. ${ }^{2}$ \\ 1 Candidato a Doctor en Derechos Fundamentales por la Universidad Carlos III de Madrid, España. Correo electrónico: \\ joaquinarmandos@yahoo.com. \\ 2 Coordinación de la Coalición Española de la Campaña Mundial por la Educación/Entreculturales. Madrid, España. Correo \\ electrónico: ygcerdeira@yahoo.es. Las opiniones aquí vertidas no comprometen a institución alguna.
}

Recibido: mayo de 2008 / Aceptado: mayo de 2008

EN LA ACTUALIDAD EL FENÓMENO MIGRATORIO SE HA CONSTITUIDO EN EL mayor desafío para las sociedades desarrolladas, especialmente de Europa y Estados Unidos, ya que pone a prueba los valores de libertad, igualdad y fraternidad que fundamentan el discurso emancipador de los derechos humanos que dichas regiones promueven desde hace más de 200 años. Paradójicamente, mientras se sigue proclamando la universalidad de tales derechos y la igualdad de las personas, la práctica de los países desarrollados se caracteriza por la implementación de políticas migratorias restrictivas y de criminalización que condenan a la ilegalidad a millones de personas. En este sentido, la intención de este artículo es aportar una prueba más de la esquizofrenia que subyace en la actitud de los países receptores en torno a la migración, pues por un lado proclaman una visión de los derechos humanos de todas las personas sin discriminación alguna, pero por otro lado, tal visión se fractura cuando un migrante llega a sus fronteras, y sus derechos, que deberían ser reconocidos "universalmente", se esfuman ante la exigencia de un documento que finalmente determina si tiene o no derechos.

Palabras clave: Migración / discurso y práctica / derechos humanos / comunidad internacional / tratados internacionales de derechos humanos

\section{Introducción}

En las últimas décadas, la migración se ha convertido en una de las manifestaciones más agudas de la crisis social y económica que golpea a diferentes regiones del mundo; en el caso específico de América Latina el aumento de los movimientos migratorios está asociado a la implementación de un modelo económico que ha aumentado la pobreza y ha expandido la marginalidad rural y urbana, condenando a la exclusión social a un alto porcentaje de la población, que directa o indirectamente se ve forzado a buscar opciones de sobrevivencia en otros países, especialmente en los más ricos y desarrollados (PIDHD 2008:13). 
Paradójicamente, mientras estos grupos humanos son expulsados por sus propios gobiernos al privarlos de las condiciones necesarias para vivir dignamente, su aporte en remesas es fundamental para el sostenimiento económico de los países de origen, y en consecuencia, para reducir el conflicto social que genera la pobreza. A su vez, a pesar de que su trabajo representa una contribución importante para la economía de los países receptores -que se benefician de la juventud y la fuerza de trabajo de los países emisores ${ }^{1}$-, las personas migrantes son una de las poblaciones de mayor vulnerabilidad y víctimas fáciles de violaciones a sus derechos humanos.

Debido a ello, el fenómeno migratorio ha cobrado una trascendencia sin precedentes en la agenda y el debate político de muchos gobiernos y de la comunidad internacional, lo cual ha motivado a que se tomen medidas para garantizar que las personas que se desplazan de un país a otro puedan ejercer sus derechos que les confiere el derecho internacional. Entre tales medidas destaca la adopción en 1990 de la Convención internacional sobre la protección de los derechos de todos los trabajadores migratorios y de sus familiares (en adelante la Convención de 1990) por parte de la Organización de las Naciones Unidas (en adelante la ONU). Pese a ello, la mayoría de los trabajadores migrantes siguen corriendo serios riesgos de explotación y abuso porque tienen poco poder para hacer valer sus derechos y porque muchos Estados no respetan las normas de derechos humanos que han prometido cumplir.

En esta línea, el presente artículo tiene como objetivo mostrar a grandes rasgos cómo el discurso liberador de los derechos humanos, teóricamente dirigido a todas las personas, parece tener efectos prácticos únicamente para los ciudadanos y los migrantes documentados que se encuentran en los países receptores, especialmente en las sociedades ricas y desarrolladas de Europa y América del Norte, mientras los migrantes "sin papeles", son condenados a un limbo jurídico que aumenta su vulnerabilidad. Paradójicamente, en estas dos regiones del mundo donde nacen los derechos humanos como concepto histórico, su disfrute efectivo se ve condicionado al estatus migratorio y por tanto, la proclamación de que "las personas nacen y permanecen libres e iguales en derechos" queda reducida a un simple mito político y jurídico.

\section{El proceso de concreción de los derechos de las personas migrantes}

La historia moderna de los derechos humanos ha estado marcada por varios momentos importantes que, con la adopción de ciertos documentos de gran influencia nacional e internacional, han significado un avance fundamental en la lucha por la dignidad humana. Por su relevancia política y jurídica podemos señalar que la Declaración de los Derechos del Hombre y del Ciudadano de 1789 (en adelante la Declaración Francesa) y la Declaración Universal de Derechos Humanos de 1948 (en adelante la Declaración Universal), representan el parteaguas que marca el inicio de una nueva era caracterizada (i) por la adopción generalizada de los principios fundamentales del derecho constitucional moderno en el que los derechos humanos constituyen un elemento esencial de legitimación de todo poder -público y privado-, y (ii) por la aceptación de la internacionalización del reconocimiento, promoción y tutela de tales derechos por encima de las fronteras nacionales que conlleva el consentimiento de que su protección ya no es más un asunto exclusivo de la competencia interna de los Estados, sino de toda la comunidad internacional. En otros términos, estos 
documentos representan dos de los hitos históricos más trascendentales en el lento y penoso camino de la consagración normativa de los derechos humanos, a los cuales les imprimieron el carácter de universalidad (Rodríguez y Rodríguez 1991:198-199).

Como concepto histórico, los derechos humanos han pasado por varias fases de desarrollo que nos ofrecen una visión general del largo proceso recorrido hasta nuestros días y que nos facilitan la detección de las contradicciones y paradojas del discurso de los derechos humanos, sobre todo hoy cuando el fenómeno de las migraciones pone a prueba los valores sobre los que descansa dicho discurso: la libertad, la igualdad y la fraternidad.

En primer lugar, el proceso de positivación supuso la toma de conciencia de la necesidad de dotar a los derechos -que aparecieron en un primer momento histórico como derechos naturales- de un estatuto jurídico que permitiera su aplicación eficaz y la protección real de sus titulares, ya que sin su incorporación al corpus juris constitucional o internacional, quedan relegados al ámbito de los valores y de los ideales morales (Peces-Barba 1999:156160); en segundo lugar, el proceso de generalización supuso una profunda transformación para convertir en efectivas las afirmaciones de las primeras declaraciones de que las personas "nacen y permanecen libres e iguales en derechos", ya que en la realidad los derechos eran disfrutados, a principios del siglo XIX, exclusivamente por la burguesía, mientras extensas capas de la población permanecían al margen de sus beneficios. Por ello, si bien es cierto que los derechos humanos nacieron como "expresión ideológica del triunfo de la burguesía" (Díaz 1981:29), destinados a proteger un grupo específico de la sociedad -el hombre, el blanco y el propietario-, también es innegable que con este proceso de generalización su reconocimiento se ha ido ampliando progresivamente a un número de personas cada vez mayor (Peces-Barba 1990:11-12).

En tercer lugar, la adopción de la Carta de la Organización de las Naciones Unidas (en adelante la Carta) y de la Declaración Universal representa la máxima expresión del proceso de internacionalización de los derechos humanos, dado que se da un proceso de humanización y socialización del derecho internacional a través del reconocimiento de la dignidad humana, lo cual propició las condiciones favorables para considerar a las personas sujetos del derecho internacional como portadoras de unos derechos que los Estados deben salvaguardar y que generan un tipo de obligaciones que todos los Estados deben cumplir (Carrillo 1999:16). Finalmente, se da un proceso de especificación de los derechos humanos que supone el paso de una titularidad genérica y abstracta a una titularidad concreta; es decir, se pasa de los derechos de la persona en abstracto, a los derechos de las personas situadas y concretas, y en situaciones especiales de vulnerabilidad que exigen una mayor protección, como ser, los derechos del niño, de la mujer, del consumidor, de los pueblos indígenas, de los trabajadores, del migrante, etc. (Bobbio 1991:15).

Es en el marco de los procesos de generalización y especificación que se sitúan los esfuerzos por garantizar el respeto de los derechos humanos de las personas migrantes, comenzando con la celebración de la Primera Conferencia Mundial para Combatir el Racismo y la Discriminación Racial, celebrada en Ginebra en 1978, en la que se recomienda la elaboración de una convención especial sobre los derechos de los trabajadores migratorios. Posteriormente, la Asamblea General de la ONU formuló una recomendación destinada a 
tomar todas las "medidas para mejorar la situación y garantizar el respeto de los derechos humanos y la dignidad de todos los trabajadores migratorios" (Resolución 33/163). Fue así como en diciembre de 1979, se decidió crear un grupo de trabajo abierto para que elaborara dicha Convención, proceso que duró 10 años (1980-1990) y que culminó con la aprobación y apertura a firma, ratificación y adhesión de la Convención del 90, la cual constituye un paso concreto para la protección de los derechos de los trabajadores migratorios al establecer un modelo moral y jurídico a seguir por los Estados del mundo.

En términos generales podemos señalar que el objetivo principal de esta Convención es que los trabajadores migratorios tengan garantizado el goce y ejercicio de todos sus derechos -independientemente de su estatus migratorio- durante todo el proceso de migración que comprende (i) la preparación para la migración, (ii) la partida, (iii) el tránsito (iv) y todo el período de estancia y de ejercicio de una actividad remunerada en el Estado de empleo, así como el regreso al Estado de origen o al Estado de residencia habitual. Está estructurada de una manera práctica que permite identificar primero un Preámbulo en que los Estados (i) ratifican los principios universalmente aceptados sobre la protección de los derechos humanos; (ii) reconocen los altos niveles de vulnerabilidad en que viven los trabajadores migratorios y sus familiares, lo cual involucra a millones de personas y afecta a gran número de países en el mundo; y (iii) reconocen que la condición irregular o regular de un trabajador migratorio no significa que sus derechos pueden ser violados.

El contenido de la Convención se encuentra diseminado a lo largo de nueve partes en las que se distribuyen los 93 artículos con que cuenta. En la primera parte se establecen los alcances y definiciones de la misma, y señala que se aplica "a todos los trabajadores migratorios y a sus familiares sin distinción alguna por motivos de sexo, raza, color, idioma, religión o convicción, opinión política o de otra índole, origen nacional, étnico o social, nacionalidad, edad, situación económica, patrimonio, estado civil, nacimiento o cualquier otra condición”, y durante todo el proceso de migración, "que comprende la preparación para la migración, la partida, el tránsito y todo el período de estancia y de ejercicio de una actividad remunerada en el Estado de empleo, así como el regreso al Estado de origen o al Estado de residencia habitual" (art. 1.1).

En la segunda parte se establece la obligación de los Estados de "respetar y asegurar a todos los trabajadores migratorios y sus familiares que se hallen dentro de su territorio o sometidos a su jurisdicción los derechos previstos en la presente Convención, sin distinción alguna por motivos de sexo, raza, color, idioma, religión o convicción, opinión política o de otra índole, origen nacional, étnico o social, nacionalidad, edad, situación económica, patrimonio, estado civil, nacimiento o cualquier otra condición” (art. 7). En la tercera parte reconoce los derechos de los trabajadores migratorios, tanto aquellos que se encuentran en una situación regular como los que se hallan en situación irregular, reafirmando de este modo el principio sobre el cual toda persona, sea nacional o extranjera, que se encuentra bajo la jurisdicción de cualquier Estado, tiene el derecho a que éste le garantice el goce y ejercicio de todos los derechos humanos reconocidos en los instrumentos internacionales ratificados por dicho Estado. Es importante resaltar que la Convención de 1990 reconoce los derechos de las personas indistintamente de su estatus migratorio (arts. 8-35). 
En su cuarta parte reconoce otros derechos a los trabajadores documentados y sus familiares (arts. 36-56); y en los restantes apartados establece la necesidad de favorecer la migración regular, la adopción de medidas para promover condiciones satisfactorias, equitativas y dignas para los migrantes y la adopción de medidas contra el ingreso irregular y la imposición de sanciones a las personas, grupos o entidades que se aprovechen de la vulnerabilidad de los migrantes para promover la migración irregular.

También hay que destacar que la Convención de 1990 reconoce que los migrantes deben gozar de un trato que no sea menos favorable que el que reciben los nacionales del Estado de empleo en lo relacionado con el salario, la seguridad social, atención médica para preservar su vida y para evitar daños irreparables a su salud, los derechos a la libertad de movimiento, a la formación de asociaciones y sindicatos y a participar en los asuntos públicos, el respeto a su identidad cultural y los vínculos culturales con sus países de origen, así como el facilitar la reunión de los trabajadores migratorios documentados con sus cónyuges o con aquellas personas que mantengan con el trabajador una relación que produzca efectos equivalentes al matrimonio. Asimismo, el derecho a que todos los hijos de los trabajadores migratorios gocen del acceso a la educación en condiciones de igualdad de trato con los nacionales del Estado de empleo. Por otro lado, también contiene una serie de disposiciones específicas referentes a la igualdad de trato de los migrantes regulares o documentados en relación con el acceso a la educación, la formación profesional, los servicios sanitarios, la vivienda y los derechos culturales.

Sin duda, esta Convención representa un avance importante en el reconocimiento normativo de los derechos humanos de todos los migrantes, independientemente de su estatus migratorio, y se constituye, junto con la Declaración Universal y otros tratados internacionales, en un instrumento fundamental e indispensable para atacar de raíz las causas que provocan la migración forzada y que condenan a la ilegalidad a millones de personas cuya dignidad es vulnerada por países democráticos que promueven un discurso de respeto por los derechos humanos pero que lo contradicen en la práctica mediante sus políticas migratorias restrictivas y de criminalización. Por tal razón, no es extraño constatar que hasta la fecha, de los 37 países que han ratificado la Convención de 1990, ninguno pertenece al mundo enriquecido y desarrollado, pese a que la mayoría de trabajadores migratorios (100 de un total de 175 millones) viven en Europa, Estados Unidos y Canadá. Tampoco la han ratificado otros países que reciben grandes cantidades de migrantes como India, Japón, Australia y los Estados del Golfo; solamente lo han hecho países que expulsan decenas de miles de migrantes cada año, tales como México, Marruecos, Lesotho, Honduras, Guatemala, Filipinas, El Salvador, Nicaragua, entre otros.

A pesar de esta falta de ratificación por parte de los países desarrollados, para los países centroamericanos el hecho de que la Convención de 1990 haya sido ratificada por México y Guatemala implica que tenemos entre manos una herramienta fundamental para exigir que estos países, por donde obligatoriamente pasan miles de migrantes con destino a Estados Unidos, prevengan, respeten y promuevan sus derechos humanos e investiguen y sancionen a los responsables de las violaciones de los mismos, ya sean particulares o funcionarios públicos, so pena de incurrir en responsabilidad internacional. De cualquier forma, no se puede ignorar que el bajo número de ratificaciones genera un impacto limitado de esta 
Convención, ya que la mayoría de Estados ven con recelo el hecho que el reconocimiento de los derechos de los migrantes indocumentados implicaría la adopción de medidas legislativas y de otra índole para revertir y cambiar las políticas restrictivas que criminalizan la migración y que convierten sus fronteras en verdaderas fortalezas, con su consecuente mantenimiento del statu quo entre la opulencia del Norte y la miseria del Sur. ${ }^{2}$

Como consecuencia, y aún a pesar de la vigencia de otros instrumentos internacionales de protección a los derechos humanos como la propia Declaración Universal y los Pactos de 1996 -el de derechos civiles y políticos, y el de derechos económicos, sociales y culturales, la violencia contra la población migrante continúa y se perpetúa bajo el amparo de la impunidad y la vulnerabilidad que ofrece la migración irregular, en la que millones de personas arriesgan sus vidas huyendo de la miseria siendo vistos, contrariamente, como "intrusos", "usurpadores", "ilegales", en vez de víctimas de un sistema que se alimenta de carne humana exportada por los filántropos del Fondo Monetario y del Banco Mundial ${ }^{3}$, en palabras de Eduardo Galeano.

\section{Las verdades del discurso y las prácticas de los enunciadores}

Anteriormente señalamos que ni los países europeos ni Estados Unidos han ratificado la Convención de 1990. Paradójicamente, en estas regiones del mundo nacen los derechos humanos mediante la elaboración de las distintas declaraciones adoptadas en los siglos XVI y XVII, cuyos valores de libertad, igualdad y dignidad humana han fundamentado una concepción del ser humano igual en derechos y "libre del temor y la miseria”, la cual se ha generalizado y ha sido aceptada como un fin que deben perseguir los Estados que se precien democráticos y civilizados.

No obstante, más de 200 años después de la adopción de la Declaración Francesa, sus valores han quedado reducidos, para millones de personas en el mundo, a una "libertad contra la igualdad y contra la solidaridad" (González 2002:2) y las "grandes promesas de la modernidad permanecen incumplidas" o su cumplimiento "ha redundado en efectos perversos" 4 , los cuales se sienten con mayor intensidad en la periferia de los países desarrollados. En el mismo sentido, ahora que estamos a punto de conmemorar el $60^{\circ}$ aniversario de la adopción de la Declaración Universal, el ejercicio de los derechos en ella contenidos siguen siendo conceptos vacíos y una utopía lejos de alcanzar en muchas partes del mundo. Su universalidad se quiebra cada vez que se pretende que se reconozcan esos derechos a los migrantes, a "los no ciudadanos", con lo que se constata que la ciudadanía se constituye en la actualidad en el último privilegio de estatus, el último factor de exclusión y discriminación, el último residuo pre-moderno de la desigualdad personal en contraposición a la proclamada universalidad e igualdad de los derechos humanos (Ferrajoli 1999:117).

Por ello, ahora que el fenómeno de la migración pone a prueba los valores de libertad e igualdad que acompañan los discursos de las sociedades desarrolladas y democráticas, el criterio de la ciudadanía parece fortalecerse cada vez más, sobre todo en las regiones y países más ricos, lo que está generando una nueva clase de sujetos que viven bajo la sombra de la ilegalidad como producto de la migración indocumentada y su tratamiento. En este sentido, sólo basta constatar la forma en que es manejada la migración por parte de los Estados 
desarrollados para darnos cuenta que su discurso universal de los derechos humanos contrasta con sus prácticas institucionales. "Se afirma de forma reiterada la defensa de los derechos humanos y al mismo tiempo se construye un modelo de injusticia estructural global. Este es un paradigma esquizofrénico (o cínico) que insiste de forma exhaustiva en la defensa formal de los derechos humanos y produce estructuras e instituciones de negación real de los mismos" (Bartolomé 2006:37-38).

Así mismo, también existe un discurso interno que moldea diariamente la opinión pública de los países ricos, un discurso alarmista y paranoico frente al peligro, la amenaza, la invasión y la avalancha que constituyen las personas migrantes. El migrante se convierte en la encarnación del nuevo enemigo, culpable de todas las crisis, por lo que su tratamiento debe estar a la altura de otros graves problemas de la humanidad como el narcotráfico y el terrorismo. En el caso europeo, sólo es cuestión de leer los textos oficiales de la Unión Europea y de la mayoría de sus Estados miembros para comprobarlo: "la lucha contra la ‘inmigración clandestina, la droga, la criminalidad y el terrorismo' es una fórmula hoy común en el lenguaje para comparar así la inmigración y formas de delincuencia. Como es moneda corriente la asimilación de la inmigración con la inseguridad, la violencia de los barrios periféricos, el miedo a los vecinos en los barrios pobres" (Naïr 2006:13-14).

En ese orden de ideas, la Unión Europea y Estados Unidos manejan un discurso de adhesión a unos valores fundamentales concretados en los derechos humanos, pero ante los retos actuales que plantea la migración parecen dispuestos a negarlos en la práctica. Además de los ya conocidos "Corralones" en Estados Unidos, también conviene echar un vistazo a los nuevos "campos de concentración" en que se han convertido los llamados "campos de internamiento ilegales para extranjeros" que forman parte "de una auténtica política europea de seguridad en materia de inmigración que subcontrata el control y la represión de ésta a los países situados fuera de las fronteras de Europa, a los que, en general, el respeto de los derechos humanos no les quita el sueño" (Naïr 2006:153). Desafortunadamente, este tipo de situación se ha generalizado a tal punto que no es una simple excepción, sino que es parte de una institucionalización como herramienta de gestión de los flujos migratorios en Europa. Por tanto, la política migratoria promovida por las autoridades europeas descansa esencialmente en la contradictoria idea de que la inmigración es a la vez una necesidad debido a las exigencias del mercado laboral y una amenaza debido a que la presión migratoria es muy importante y el desempleo cada vez mayor en Europa. De esta forma, se esclarece que los países desarrollados mantienen una concepción utilitarista de la inmigración, esencialmente determinada por las necesidades del mercado laboral europeo o estadounidense; por tanto, la migración que se constituye en la única forma de sobrevivencia para millones de personas en el mundo, es concebida por los Estados receptores como una simple mercancía. ${ }^{5}$

Con este escenario, se puede concluir que en la actualidad existen tres categorías de personas que viven en los países ricos y desarrollados, especialmente en Europa: (i) los nacionales que disponen de todos sus derechos; (ii) los ciudadanos europeos que disponen tendencialmente de derechos equivalentes; y (iii) aquellos a los que se les aplica el derecho de los extranjeros, los migrantes, que generalmente llevan mucho tiempo instalados en ese continente (Naïr 2006:201-202). Pero también es necesario resaltar que dentro de la tercera 
categoría se pueden identificar dos sub-categorías: (a) el migrante documentado, al que se le reconocen derechos más o menos razonables, pero de muy complicado acceso; y (b) el migrante indocumentado o el mal llamado "ilegal”, al que se culpabiliza y criminaliza por su situación de ilegalidad y de vulnerabilidad, impidiéndole además salir de ella (Lucas 2004:83). Finalmente, dentro de esta última sub-categoría se encuentran (a.i) aquellos migrantes que viven y trabajan de forma clandestina en los países receptores; y (a.ii) aquellos que se encuentran detenidos en los mencionados campos de internamiento.

En consecuencia, de cara a la titularidad y al ejercicio de los derechos humanos, se puede sostener que estas dos últimas clases de sujetos se encuentran dentro del estatus de "los socialmente insignificantes", de "los nadie", ${ }^{6}$ lo que plantea serios desafíos para la democracia y el Estado de derecho, ya que indudablemente todas estas divisiones son injustas, no igualitarias y generadoras de todo tipo de conflictos al vulnerar el principio de igualdad en tanto que existe una distinción en derechos entre inmigrantes, y entre inmigrantes y ciudadanos, y para el principio de control popular, en tanto que existe una población inmigrante que se ve afectada directamente por las decisiones políticas sobre las que no tiene los mecanismos para controlarlas (Zapata 2004:208-210).

\section{Conclusiones}

No hay duda de que este divorcio entre el discurso y los hechos responde a la necesidad del actual sistema económico de convertir a la migración en un vector fundamental de la ley de la oferta y la demanda, gestionada por y para el mercado. Y en esta gestión, tanto los Estados de origen y de destino, así como las fuerzas del mercado, conviven en perfecta armonía y complicidad (Naïr 2006:200). Ciertamente la crudeza de la realidad descrita puede generar un pesimismo que implique una actitud conformista frente ella. Sin embargo, es necesario denunciar esta concepción restringida de los derechos que contradice las propias cartas constitucionales que adscriben algunos de ellos a todas las personas, y también denunciar los tratados internacionales que los garantizan en general sin imponer ningún tipo de criterio, pues de esta forma se devela la ilegitimidad de la desigualdad y de las fronteras y, con ello, se da el primer paso necesario para una profunda movilización democrática, es decir, la concientización de los diferentes sectores de la sociedad (Pisarello y Suriano 1998:192).

Evidentemente, de la noche a la mañana no se pueden detener los flujos migratorios ni acabar con las causas que los provocan. Lo que sí es posible hacer ya es (i) lograr que todo tratamiento al fenómeno de la migración se realice con estricto apego al respeto de los derechos humanos, pues aunque los Estados tienen el derecho soberano de decidir quién puede entrar y permanecer en su territorio y en qué condiciones, ello no es justificación para promover acciones y políticas racistas y xenófobas; y (ii) garantizar la solución de los problemas de pobreza y desarrollo de los países expulsores de migrantes, lo que implica tomar en serio la necesidad de cambiar el actual modelo de relaciones internacionales desiguales, de la ayuda al desarrollo que muchas veces es sustituida por la concesión de préstamos en condiciones severas, de reconocer la ilegitimidad e ilegalidad de la deuda externa, de cambiar el intercambio comercial perfectamente diseñado para garantizar a las grandes empresas y a los países más ricos actuar con total libertad y sin ningún tipo de 
obstáculo ético o jurídico en relación con los derechos humanos, condenando a los países más pobres a la continua dependencia y subdesarrollo; y en conclusión, ampliar el concepto de libertad, lo que supondría que los hombres y mujeres de todas partes del mundo puedan verse "libres de la miseria, de manera que se levanten para ellas las sentencias de muerte que imponen la pobreza extrema y las enfermedades infecciosas" (Annan 2005:5-6).

Es de destacar que lo anteriormente expuesto no es un asunto que solamente pertenece al mundo de los deberes morales, sino que también constituye una obligación jurídica de los Estados desarrollados, ya que en el caso de los países miembros de la Unión Europea, y en menor medida Estados Unidos, todos ellos han adoptado la mayoría de normas consuetudinarias y convencionales internacionales cuyas disposiciones -especialmente las de los tratados de derechos humanos- son de obligatoria observancia, y cuya transgresión genera la responsabilidad internacional de los Estados que las incumplen.

Sin embargo, hay que tener presente que estos instrumentos internacionales deben verse como uno de los varios mecanismos para luchar por la dignificación de la migración, y a la par de esta lucha jurídica, también es necesaria la lucha política, ya que sólo a través de la batalla por los derechos humanos y su constante ejercicio y defensa tenaz frente a todo obstáculo posible, amenaza o violación, se puede garantizar su posesión efectiva y la consiguiente valorización de la persona, independientemente de su condición migratoria. En ese sentido, es claro que los derechos humanos no caen nunca del cielo, ni tampoco son algo dado y construido de una vez por todas con la Revolución Francesa de 1789 o con la adopción de la Declaración Universal de 1948, sino que se trata de procesos llenos de dinámicas y de luchas históricas como resultado de la resistencia de individuos y colectivos contra las diversas formas violentas de manifestación del poder (Herrera 2005:219).

La historia ya nos ha demostrado en repetidas ocasiones que dentro de estas manifestaciones violentas del poder van surgiendo grietas que han permitido la construcción de espacios fundados en los derechos humanos como agentes de emancipación y cambio. De esta forma, la burguesía del siglo XVIII resistió y rompió el sistema de relaciones mantenido por el Ancien Régime, logrando el reconocimiento de los derechos del hombre y del ciudadano, que desafortunadamente se restringió al hombre, al blanco y al propietario. Sin embargo, los sectores marginados de las ventajas de ese proceso emancipatorio impulsaron con sus luchas nuevas grietas que permitieron desbordar los límites de las fronteras burguesas y universalizar el disfrute de esos derechos a sectores cada vez más amplios de la sociedad. ${ }^{7}$

Por consiguiente, la superación de los distintos criterios de inclusión/exclusión, incluida la ciudadanía, es una cuestión urgente que sólo podrá realizarse concibiendo los derechos humanos como procesos de lucha que transformen profundamente las estructuras económicas, sociales, políticas y jurídicas del antidemocrático modelo de la sociedad globalizada. Ello implica cuestionar y replantear el argumento de que las personas, debido a su condición migratoria, no se pueden beneficiar de los valores democráticos y del ejercicio pleno de los derechos que les corresponden como seres humanos, ya que si se mantiene el abismo existente entre el proclamado universalismo de los derechos humanos y la práctica cotidiana que niega el disfrute de los mismos a la gran mayoría del género humano que contingentemente nació en la periferia del mundo desarrollado, será insostenible mantener 
la credibilidad de un modelo de sociedad democrática y de Estado de derecho, cuya característica fundamental es el respeto de todos los derechos humanos a todos.

\section{Notas}

1 "Las nuevas corrientes migratorias [...] reflejan las condiciones de la economía en los países de origen y destino de los migrantes. En éstos operan factores de atracción que reclaman el aporte de la mano de obra de esos trabajadores, que concurren a la creación de riqueza y contribuyen de manera muy significativa -como han reconocido los analistas de estos procesos- al bienestar y desarrollo de los países receptores [...] Las condiciones en que se producen algunos de estos procesos y los resultados que tienen implican, de hecho, una especie de subsidio a las economías más desarrolladas, además de su significado como fuente de recursos para los migrantes que prestan sus servicios en aquellas y para las familiares que residen en los lugares de procedencia" (García OC-18/2003: párr.6).

2 Como lo señala Lucas, "si los inmigrantes no vienen, si no se hacen visibles con sus duras biografías a cuesta, nada impulsará al mundo satisfecho a revertir la violenta organización del mundo que hemos consentido" (Lucas 2004:85).

3 Galeano, E. (13 de nov. de 2005) Objetos prohibidos. APIA (Agencia Periodística de Información Alternativa). Disponible en: http://www.apiavirtual.com/2005/11/14/articulo-8937/. Consultado el 04 de abril de 2008.

4 En lo que concierne a la promesa de igualdad, los países capitalistas avanzados con el 21\% de la población mundial controlan el $78 \%$ de la producción mundial de bienes y servicios y consumen el $75 \%$ de toda la energía producida [...] En el siglo XX han muerto más personas por hambre que en cualquiera de los siglos precedentes. La distancia entre países ricos y países pobres y entre ricos y pobres en el mismo país no ha cesado de aumentar [...] En lo que respecta a la promesa de libertad, las violaciones de los derechos humanos en países que viven formalmente en paz y democracia asumen proporciones avasalladoras [...] En lo concerniente a la promesa de paz perpetua, que Kant formuló tan elocuentemente, mientras que en el siglo XVIII murieron 4,4 millones de personas en 68 guerras, en el siglo XX murieron 99 millones de personas en 237 guerras. Entre el siglo XVIII y el siglo XX, la población mundial aumentó 3,6 veces, mientras que los muertos por guerras aumentaron 22,4 veces [...] Finalmente, la promesa de dominación de la naturaleza ha sido cumplida de un modo perverso bajo la forma de su destrucción y de la crisis ecológica. Apenas dos ejemplos. En los últimos 50 años el mundo perdió cerca de un tercio de su cobertura forestal. A pesar de que el bosque tropical proporciona el $42 \%$ de la biomasa vegetal y de oxígeno, 600.000 hectáreas de bosque mexicano son destruidas anualmente. Las empresas multinacionales detentan hoy derechos de tala de árboles en 12 millones de hectáreas en la selva amazónica (Sousa 2003:23-25).

5 Estos centros instalados fuera del espacio comunitario son muy heterogéneos en cuanto a sus dispositivos administrativos (cerrados/abiertos) y su nivel de institucionalización (oficiales/informales). La característica común es, no obstante, la indeterminación de su estatuto jurídico y de su duración. Contamos con pocos datos precisos, y menos aún con estadísticas sobre la existencia de estos campamentos, su ubicación geográfica, número de personas que residen en ellos, estancia media o condiciones de internamiento. En pocas palabras, el silencio sobre lo que ocurre en esos lugares sin nombre es prácticamente total y está muy bien organizado [...] A los periodistas e investigadores independientes les resulta muy difícil acceder a ellos, salvo con motivo de alguna que otra visita oficial de los organismos internacionales [...] Además, estas visitas suelen estar preparadas y la idea que de ellas se saca no tiene nada que ver con la experiencia de los extranjeros que han residido en esos centros (Naïr 2006:154).

6 El término "los socialmente insignificantes" corresponde al Teólogo Gustavo Gutiérrez y el de "los nadie" a Eduardo Galeano.

$7 \quad$ En ese contexto se inscriben "la lucha de Olimpo de Gouges por sus reivindicaciones de género; Babeuf y su lucha por la sustitución de la igualdad formal ante la ley por una igualdad real de todos; Toussaint L'Ouverture y sus prácticas antiesclavistas y antirracistas; 0 , por poner un punto final, Marx y su análisis científico del funcionamiento del capitalismo como base de prácticas alternativas a los mecanismos de explotación del capital. Todos estos actores antagonistas lucharon teórica y prácticamente contra el determinismo de esa fuerza inscrita en las relaciones sociales, construyendo las posibilidades de otro proceso -de la inscripción de otra fuerza- en la que esos derechos de los ciudadanos no funcionaran como obstáculos para prácticas sociales diferentes. ¿Qué decir de los movimientos feministas de los años setenta y ochenta empeñados en lucha antipatriarcalista? ¿Dónde debemos contextualizar los esfuerzos de los colectivos negros, latinos, indígenas sino en la construcción de nuevos procesos y nuevos espacios de lucha por la dignidad humana?" (Herrera 2005:221-223). 


\section{Referencias bibliográficas}

ANNAN, K. (2005) Un concepto más amplio de la libertad: Desarrollo, seguridad y derechos humanos para todos. Informe del Secretario General de Naciones Unidas, Barcelona: Asociación para las Naciones Unidas en España y Federación de Asociaciones de Defensa y Promoción de Derechos Humanos.

BARTOLOMÉ, C. (2006) El Movimiento de los Sin Tierra en Brasil.Propiedado alteridad, dilema de los derechos humanos, Bilbao: Instituto de Derechos Humanos, Universidad de Deusto.

BOBBIO, N. (1991) El tiempo de los derechos, trad. de Rafael de Asís Roig, Madrid: Sistema.

CARRILLO, J. (1999) Dignidad frente a barbarie. La Declaración Universal de Derechos Humanos, cincuenta años después, Madrid: Trotta.

CORTE INTERAMERICANA DE DERECHOS HUMANOS (Sentencia de 28 de febrero de 2003), Caso “Cinco Pensionistas" vrs. Perú, Serie C No 98, voto concurrente razonado del juez Sergio García Ramírez.

DÍAZ, E. (octubre 1981) Estado de derecho y sociedad democrática, Madrid: Taurus Ediciones (1966), Madrid, $8^{\mathrm{a}}$ ed. (rev.).

FERRAJOLI, L. (1999) "De los derechos del ciudadano a los de la persona", en Íd., Derechos y garantías. La ley del más débil, trad. de Perfecto Andrés Ibáñez y Andrea Greppi, Madrid: Trotta.

GONZÁLEZ, J. I. (septiembre de 2002), Abjurar la Modernidad. Pecados originales de Occidente, Barcelona: Cristianisme i Justícia, Barcelona.

HERRERA, J. (2005) Los derechos humanos como productos culturales. Crítica del humanismo abstracto, Pamplona/Madrid: Los Libros de la Catarata.

LUCAS, J. DE (2004) "Reconocimiento, inclusión, ciudadanía. Los derechos sociales de los inmigrantes", en AÑÓN, M. (Ed.), La universalidad de los derechos sociales: El reto de la inmigración, Valencia: Tirant lo Blach.

NAÏR, S. (2006) Y vendrán... Las migraciones en tiempos hostiles, trad. de María Cordón y Malika Embarek, Barcelona: Planeta.

PECES-BARBA, G. (1990) "Los derechos humanos: la moralidad de nuestro tiempo", en AA. VV., La garantía internacional de los derechos sociales, Madrid: Ministerio de Asuntos Sociales, Madrid.

PECES-BARBA, G. (1999) Curso de derechos fundamentales. Teoría general, con la colaboración de Rafael de Asís Roig, Carlos R. Fernández Liesa, Ángel Llamas Gascón, Universidad Carlos III de Madrid, Madrid: Boletín Oficial del Estado.

PLATAFORMA INTERAMERICANA DE DERECHOS HUMANOS, DEMOCRACIA Y DESARROLLO (abril de 2008) Migración y derechos humanos. Primer informe para la consulta permanente sobre migraciones y derechos humanos en América Latina y el Caribe, Bogotá: Ediciones Antropos.

PISARELLO, G. \& SURIANO, R. (octubre de 1998) “Entrevista a Luigi Ferrajoli”, en Isonomía. Revista de Teoría y Filosofía del Derecho, No 9, México.

RODRÍGUEZ Y RODRÍGUEZ, J. (1991) "Las Declaraciones Francesa y Universal de los Derechos Humanos", en AA. VV., Bicentenario de la Revolución Francesa, México: Instituto de Investigaciones Jurídicas de la Universidad Nacional Autónoma de México, $1^{\mathrm{a}}$ edición. 
SOUSA, B. DE (2003) Crítica de la razón indolente. Contra el desperdicio de la experiencia. Volumen I. Para un nuevo sentido común: La ciencia, el Derecho y la política en la transición paradigmática, Bilbao: Desclée de Brouwer.

ZAPATA-BARRERO, R. (2004) "La gestión política de la inmigración: indicadores y derechos”, en AÑóN, M. (Ed.), La universalidad de los derechos sociales: El reto de la inmigración, Valencia: Tirant lo Blach. 